\title{
Phosphor Dysprosium-Doped Layered Double Hydroxides Exchanged with Different Organic Functional Groups
}

\author{
David Ricardo Martínez Vargas, ${ }^{1}$ Mariana J. Oviedo, ${ }^{2}$ Fabio da Silva Lisboa, ${ }^{3}$ \\ Fernando Wypych, ${ }^{3}$ Gustavo A. Hirata, ${ }^{4}$ and Gregorio Guadalupe Carbajal Arizaga ${ }^{5}$ \\ ${ }^{1}$ Departamento de Farmacobiología, Universidad de Guadalajara, Boulevard Marcelino García Barragán 1421, \\ 44430 Guadalajara, JAL, Mexico \\ ${ }^{2}$ Programa de Posgrado en Física de Materiales, CICESE-UNAM, Carretera Ensenada-Tijuana No. 3918, \\ 22800 Ensenada, BCS, Mexico \\ ${ }^{3}$ Departamento de Química, Universidade Federal do Paraná, Centro Politécnico, Jardim das Américas, CP 19081, \\ 81531-980 Curitiba, PR, Brazil \\ ${ }^{4}$ Centro de Nanociencias y Nanotecnología, Universidad Nacional Autónoma de México, Km. 107 Carretera Tijuana-Ensenada, \\ Apartado, Postal 14, 22800 Ensenada, BCS, Mexico \\ ${ }^{5}$ Departamento de Química, Universidad de Guadalajara, Marcelino García Barragán 1421, 44430 Guadalajara, JAL, Mexico
}

Correspondence should be addressed to Gregorio Guadalupe Carbajal Arizaga; gregoriocarbajal@yahoo.com.mx

Received 3 May 2013; Revised 25 September 2013; Accepted 26 September 2013

Academic Editor: Tifeng Jiao

Copyright ( 2013 David Ricardo Martínez Vargas et al. This is an open access article distributed under the Creative Commons Attribution License, which permits unrestricted use, distribution, and reproduction in any medium, provided the original work is properly cited.

The layers of a $\mathrm{Zn} / \mathrm{Al}$ layered double hydroxide $(\mathrm{LDH})$ were doped with $\mathrm{Dy}^{3+}$ cations. Among some compositions, the $\mathrm{Zn}^{2+}: \mathrm{Al}^{3+}: \mathrm{Dy}^{3+}$ molar ratio equal to 30:9:1 presented a single crystalline phase. Organic anions with carboxylic, amino, sulfate, or phosphate functional groups were intercalated as single layers between LDH layers as confirmed by X-ray diffraction and infrared spectroscopy. Photoluminescence spectra of the nitrate intercalated LDH showed a wide emission band with strong intensity in the yellow region (around $574 \mathrm{~nm}$ ), originated due to symmetry distortion of the octahedral coordination in dysprosium centers. Moreover, a broad red band emission was also detected apparently due to the presence of zinc oxide. The distorted symmetry of the dysprosium coordination environment, also confirmed by X-ray photoelectron spectroscopy analysis, was modified after the intercalation with phenyl phosphonate (PP), aspartate (Asp), adipate (Adip), and serinate (Ser) anions; the emission as measured from PL spectra of these LDH was more intense in the blue region (ca. $486 \mathrm{~nm}$ ), thus indicating an increase in symmetry of dysprosium octahedrons. The red emission band from zinc oxide kept the same intensity after intercalation of dodecyl sulfate (DDS). An additional emission of unknown origin at $\lambda=767 \mathrm{~nm}$ was present in all LDHs.

\section{Introduction}

Layered double hydroxides (LDHs) are crystalline materials whose layers are composed by octahedral units either occupied by divalent or trivalent cations in coordination with hydroxyl groups. Since the electrostatic charge of trivalent cations in such coordination is not completely neutralized, additional anions intercalated between the layers are required. The chemical composition of LDHs is then represented by the general formula: $\left[\mathrm{M}^{2+}{ }_{1-x} \mathrm{M}^{3+}{ }_{x}(\mathrm{OH})_{2}\right]^{x+}$ $\mathrm{A}^{m-}{ }_{x / m} \cdot n \mathrm{H}_{2} \mathrm{O}$, where $\mathrm{M}^{2+}$ and $\mathrm{M}^{3+}$ are the cations in octahedral sites and $\mathrm{A}$ is the interlayer anion of charge $m-[1-3]$.

One of the conditions to successfully synthesize these layered structures is the radius size of $\mathrm{M}^{2+}$ and $\mathrm{M}^{3+}$ cations, which must be close to that of $\mathrm{Mg}^{2+}(0.86 \AA)[1,4]$. If the cationic radius is lower than $0.60 \AA$, the layers could be distorted and the quality of crystals is reduced [3], while if the radii are larger than $0.93 \AA$, the most probable product 
is a mixture of LDH crystalline phases with single metal hydroxides.

Recently, the synthesis of LHDs doped with $\mathrm{Eu}^{3+}$ occupying the $\mathrm{M}^{3+}$ sites was achieved [5-8] despite its large cationic radius of $1.08 \AA$ in octahedral coordination [9], thus demonstrating the possibility to introduce large cations in the layers. The introduction of europium led to obtain LDHs with fluorescent properties $[6-8,10,11]$. The fluorescence due to europium in $\mathrm{LDHs}$ has also been introduced by intercalating anionic europium complexes in the interlayer space represented by $\mathrm{A}^{m-}$ in the general formula $[10,12$, 13]; however, the first approach to produce fluorescent LDH is more attractive since the interlayer space is available for further exchange reactions [11]. This combination of fluorescence and intercalation properties in LDH structures has been proposed as an alternative to design drug delivery systems $[6,8]$ that could be monitored through light emission techniques [14]. This strategy seems feasible owing to the chemical and thermal stability of the LDHs modified with molecules for medical or biological applications $[15,16]$.

Another interesting application proposed for an europium-doped LDH is as a probe for phenylalanine detection considering that the light emission of europium into the layers shifts from the red to the blue region of the visible spectrum after the amino acid intercalation [8]. Even when this result did not correspond to a single crystalline phase compound, the change in luminescence induced by the substitution of ligands coordinating the europium centers was a novelty [8] considering that the electronic internal transitions in lanthanides should not be affected by ligands [17].

A possible way to confirm the influence of ligands on the lanthanide luminescence is by testing variety of organic ligands introduced in the interlayer space $\left(\mathrm{A}^{m-}\right.$ site) of lanthanide-doped LDHs considering that some organic ions intercalated into LDHs can be grafted to the layers [18, 19]; that is, they could directly coordinate the lanthanide center.

The objective of this work was to synthesize LDH structures containing $\mathrm{Dy}^{3+}$ cations in the octahedral sites of the layers to verify whether the layered structure is stable with this large cation, whose ionic radii $(1.05 \AA)$ is close to that of europium [9], and to study the emission spectrum of dysprosium after the intercalation of organic ions with carboxylate, amino, phosphonate, and sulfate functional groups in order to confirm the influence of ligands on the emission of the lanthanide in a single crystalline phase compound.

Finally, the paper demonstrated that the introduction of dysprosium is an advantage due to a weak emission near to the red light which opens the possibility to design biological probes since the light with this energy is able to cross biological tissues.

\section{Experimental Part}

The chemicals used in this work were $\mathrm{Zn}\left(\mathrm{NO}_{3}\right)_{2} \cdot 6 \mathrm{H}_{2} \mathrm{O}$ (Analytyka, Mexico, $98 \%$ ), $\mathrm{Al}\left(\mathrm{NO}_{3}\right)_{3} \cdot 6 \mathrm{H}_{2} \mathrm{O}$ (Analytyka, Mexico, 98\%), $\mathrm{Dy}\left(\mathrm{NO}_{3}\right)_{3}$ (Sigma-Aldrich, USA, 99\%), L-serine, Ser, (Sigma-Aldrich, USA 99\%), L-aspartic acid, Asp, (SigmaAldrich, USA, 99\%), sodium dodecylsulfate, DDS (Jalmex,
Mexico, 99\%), adipic acid, Adip, (Meyer, Mexico, 99\%), and phenyl phosphonic acid (PP) (Sigma-Aldrich, USA, 99\%). All of these materials were used as received without further purification. To avoid the co-intercalation of carbonate, decarbonated distilled water was used to prepare all the solutions and the syntheses were performed under flow of nitrogen.

2.1. Layered Double Hydroxides. The LDHs were prepared with the $\mathrm{Zn}^{2+}: \mathrm{Al}^{3+}: \mathrm{Dy}^{3+}$ molar ratios of $30: 10: 0,30: 9: 1$, and $30: 0: 10$, and these values were used as labels to identify the LDHs. All the compositions maintain the constant $\mathrm{Zn}^{2+}: \mathrm{M}^{3+}$ molar ratio equal to $3: 1$.

As example, the $\mathrm{LDH}$ with the ratio $30: 9: 1$ was prepared by dissolving $4.4709 \mathrm{~g}$ of $\mathrm{Zn}\left(\mathrm{NO}_{3}\right)_{2} \cdot 6 \mathrm{H}_{2} \mathrm{O}\left(2.36 \times 10^{-2} \mathrm{~mol}\right.$ of $\left.\mathrm{Zn}^{2+}\right)$, 2.6671 $\mathrm{g}$ of $\mathrm{Al}\left(\mathrm{NO}_{3}\right)_{3} \cdot 9 \mathrm{H}_{2} \mathrm{O}\left(7.1 \times 10^{-3} \mathrm{~mol}\right.$ of $\left.\mathrm{Al}^{3+}\right)$, and $0.2741 \mathrm{~g}$ of $\mathrm{Dy}\left(\mathrm{NO}_{3}\right)_{3}\left(7.8 \times 10^{-4} \mathrm{~mol}\right.$ of $\left.\mathrm{Dy}^{3+}\right)$ in $250 \mathrm{~mL}$ of decarbonated distilled water in a sealed vessel and purged with nitrogen. The solution was titrated with $4 \%$ ammonia solution up to $\mathrm{pH}$ 9. The white powder was recovered by decantation, washed with distilled water three times, and dried at $60^{\circ} \mathrm{C}$ to constant weight.

2.2. Intercalation of Organic Anions. The coprecipitation method was followed to obtain the LDH because this is more efficient for intercalation of amino acids [20]. The metal cations solution with the $\mathrm{Zn}^{2+}: \mathrm{Al}^{3+}: \mathrm{Dy}^{3+}$ molar ratio of $30: 9: 1$ was prepared according to the procedure described previously for the LDH. A second solution containing $0.0106 \mathrm{~mol}$ of Asp, Ser, PP or DDS, or $0.0053 \mathrm{~mol}$ of Adip in $100 \mathrm{~mL}$ of water was adjusted to $\mathrm{pH}=9$, with $4 \%$ ammonia solution, and then was added to the metal cations solution under vigorous stirring. The final $\mathrm{pH}$ was adjusted to $\mathrm{pH}=$ 9 and the stirring was kept for $18-24 \mathrm{~h}$. The powders were recovered by filtration, washed with water, and dried at $60^{\circ} \mathrm{C}$ to constant weight.

2.3. Characterization. The X-ray diffraction patterns were collected with a Shimadzu diffractometer (XDR-6000) using $\mathrm{Cu}_{\mathrm{K} \alpha}$ radiation $(0.15418 \mathrm{~nm})$ with $30 \mathrm{~mA}$ and $40 \mathrm{kV}$ and graphite crystal as monochromator; the scan step was 0.02 degrees. Fourier transform infrared (FTIR) spectra were collected in the transmission mode with a Perkin-Elmer spectrometer model Spectrum One using a resolution of $4 \mathrm{~cm}^{-1}$. Photoluminescence (PL) spectra were obtained with a fluorescence spectrometer (Hitachi FL-7000) operated with a $5 \mathrm{~nm}$ slit and $500 \mathrm{~V}$ at room temperature. A series of excitation measurements were conducted in order to determine the optimum excitation energy. X-ray photoelectron spectra (XPS) were collected with an AES-XPS PHI 548 system with $\mathrm{Al}$ anode. An energy step of $100 \mathrm{eV}$ was used for the generation of survey spectra, which was scanned from 0 to $1200 \mathrm{eV}$. For high-resolution spectra, an energy step of $50 \mathrm{eV}$ was used with $0.8 \mathrm{eV}$ resolution. The $\mathrm{Cls}$ binding energy was used to compensate surface charge effects. The electronic paramagnetic resonance (EPR) analyses were done in quartz tubes containing powdered samples which were placed in 


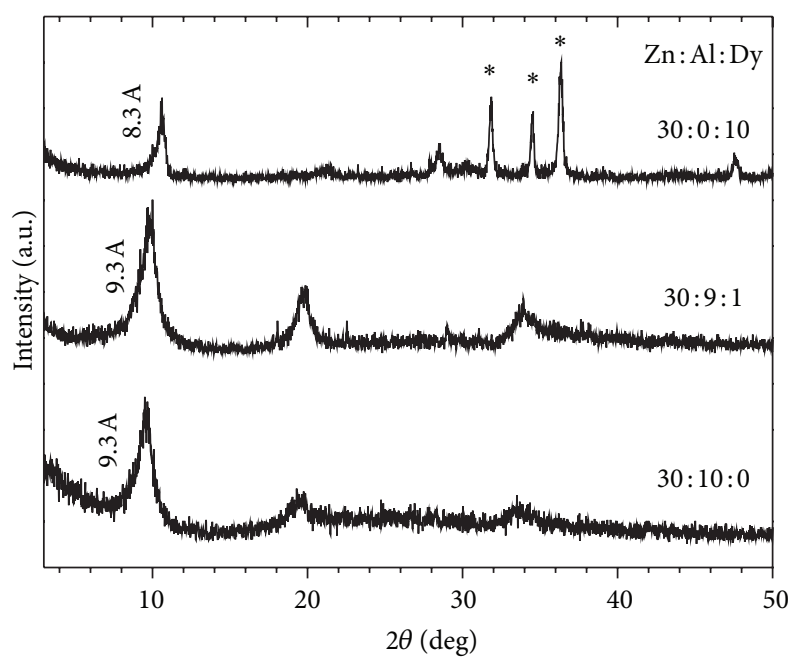

FIGURE 1: XRD profiles of LDHs with different $\mathrm{Zn}^{2+}: \mathrm{Al}^{3+}: \mathrm{Dy}^{3+}$ molar ratios. Asterisks belong to $\mathrm{ZnO}$ reflections.

a suitable support containing liquid nitrogen $(77 \mathrm{~K})$ and analyzed in a BRUKER ESP 300 E spectrometer at $9.5 \mathrm{GHz}$ (X band). For registration of the spectra, a microwave power of $2 \mathrm{~mW}$ was used, with frequency modulation of $100 \mathrm{kHz}$ and field modulation amplitude of $5 \mathrm{G}$.

\section{Results and Discussion}

3.1. Dysprosium Doped LDHs. The XRD patterns of the $30: 10: 0 \mathrm{LDH}$ presented a basal distance of $9.3 \AA$, similar to that in the $30: 9: 1 \mathrm{LDH}$, whereas the distance decreased to $8.3 \AA$ in the $30: 0: 10 \mathrm{LDH}$. These different values have been observed earlier and demonstrated to depend on the perpendicular or parallel orientation of nitrate ions with respect to the layers, respectively [21]. The orientation becomes important to define the ion-exchange capability in LDHs once parallel nitrate ions are more difficult to be exchanged [21]; then the 30:0:10 LDH would not be a suitable matrix for exchange experiments; furthermore, this compound presented a second phase of $\mathrm{ZnO}$ whose reflections are identified with asterisks in Figure 1. Therefore, the selected LDH for the intercalation study was $30: 9: 1$ because it presented a single phase; additionally, the basal distance of $9.3 \AA$ related to perpendicular nitrate anions would facilitate the ion-exchange in future works.

The FTIR analysis of the three $\mathrm{LDH}$ presented the typical wide band around $3500 \mathrm{~cm}^{-1}$ of $\mathrm{O}-\mathrm{H}$ vibrations $[5,7,22]$ and the intense signal at $1384 \mathrm{~cm}^{-1}$ of the stretching mode in the nitrate ion with $\mathrm{D}_{3 \mathrm{~h}}$ symmetry (Figure 2); that is, nitrate is free in the interlayer space [18] of $30: 10: 0$ and $30: 9: 1 \mathrm{LDH}$, which are the same structures whose XRD pattern suggested nitrate with perpendicular orientation in the interlayer space. The $30: 0: 10 \mathrm{LDH}$ presented an additional band at $1515 \mathrm{~cm}^{-1}$, which clearly appears when nitrate ions are bonded to the layers [18], contributing to reducing the basal space in addition to the parallel orientation. The bands below $550 \mathrm{~cm}^{-1}$ indicate the presence of metal-oxygen stretching and bending modes

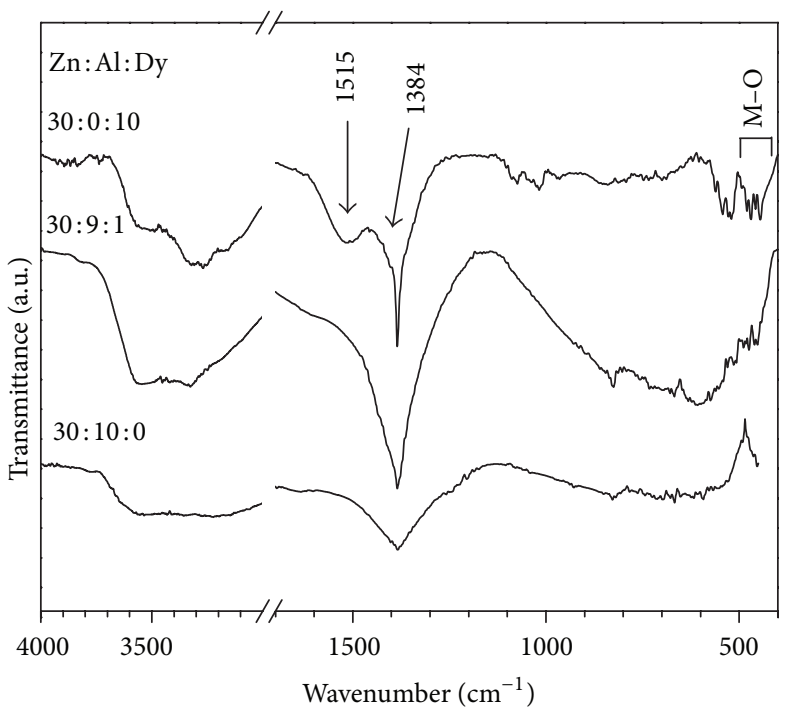

FIgURE 2: FTIR spectra of LDHs with different $\mathrm{Zn}^{2+}: \mathrm{Al}^{3+}: \mathrm{Dy}^{3+}$ molar ratios.

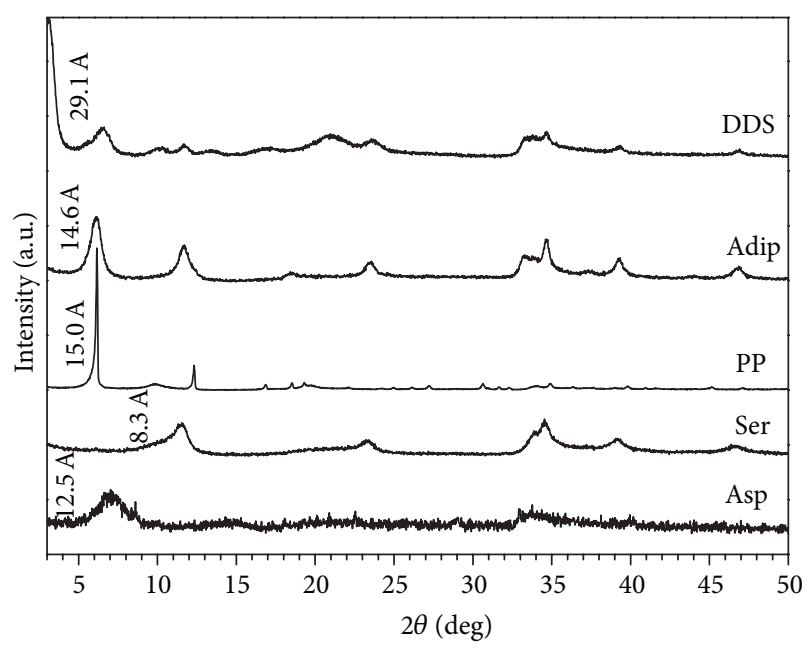

FIGURE 3: XRD patterns of the 30:9:1 LDH coprecipitated with L-aspartic acid (Asp), L-serine (Ser), phenylphosphonic acid (PP), adipic acid (Adip), and sodium dodecyl sulfate (DDS).

[23], which are associated with metals in the octahedral sites for the structures whose XRD pattern indicated a layered structure; in the case of the $30: 0: 10 \mathrm{LDH}$, the metal-oxygen vibrations belong also to zinc oxide.

3.2. Intercalation in Dysprosium-Doped LDH. The coprecipitated LDHs with organic anions were analyzed by XRD (Figure 3). The patterns of the Asp, PP, Adip, and DDS derivatives presented basal spaces of 12.5, 15.0, 14.5, and $29.2 \AA$, respectively, in agreement with the intercalation of a single organic layer in the interlayer space of the $\mathrm{LDH}$ structure $[19,20,22,24,25]$. The Ser coprecipitation product did not produce an intercalated compound since the basal space of $8.3 \AA$ corresponded to the $30: 0: 10 \mathrm{LDH}$ intercalated with nitrate ions, which is plotted in Figure 1; however, 


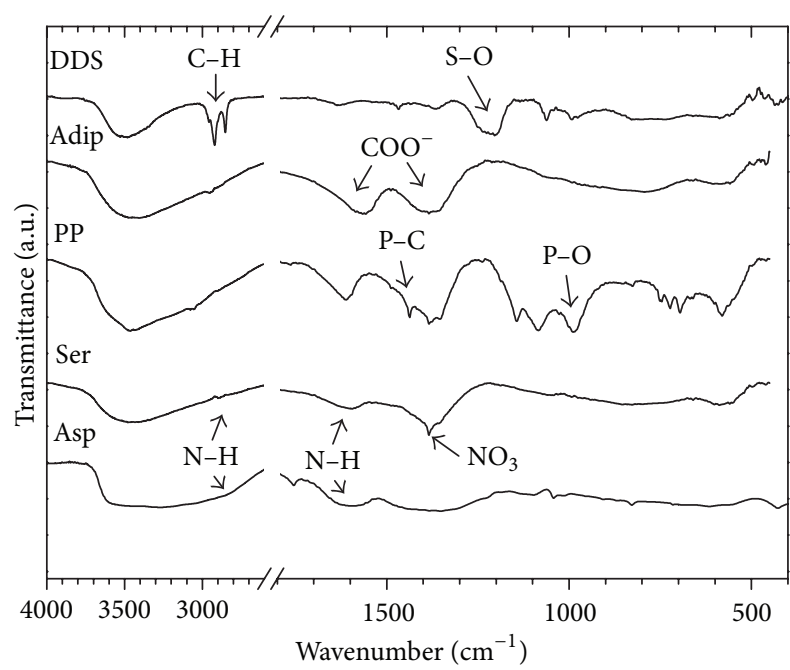

FIGURE 4: FTIR spectra of the 30:9:1 LDH coprecipitated with L-aspartic acid (Asp), L-serine (Ser), phenylphosphonic acid (PP), adipic acid (Adip), and sodium dodecylsulfate (SDS).

the surface adsorption of this amino acid was evidenced by FTIR spectroscopy.

The FTIR spectra of the organic intercalated LDHs presented in Figure 4 confirmed the presence of the corresponding anions in the LDH structures. All the products presented bands below $600 \mathrm{~cm}^{-1}$ corresponding to metaloxygen stretching modes of the inorganic layers $[5,8,20$, 24]. The Asp and Ser derivatives showed a wide shoulder at $2900 \mathrm{~cm}^{-1}$ and a signal around $1600 \mathrm{~cm}^{-1}$ of stretching modes in the amino group and wide bands at 1380 and $1550 \mathrm{~cm}^{-1}$ of carboxylate stretching modes typical of amino acids [20, 24]. Therefore, despite the Ser product was not intercalated according to the XRD pattern, the LDH particles adsorbed Ser molecules on the crystallites surface.

The bands corresponding to the organic functional groups in the spectra of LDHs coprecipitated with PP, Adip and DDS indicated the presence of organic anions: the phosphate group presented the $\mathrm{P}-\mathrm{C}$ and $\mathrm{P}-\mathrm{O}$ stretching modes at 1440 and $980 \mathrm{~cm}^{-1}$, respectively [22]; the carboxylate vibrations of adipate anions appeared at 1560 and $1400 \mathrm{~cm}^{-1}$ [18], whereas the $\mathrm{S}-\mathrm{O}$ vibration of the sulfate anion was identified at $1210 \mathrm{~cm}^{-1}$ [26] and two $\mathrm{C}-\mathrm{H}$ bands of the aliphatic chain near to $1210 \mathrm{~cm}^{-1}$ [26].

These XRD and FTIR data indicated that (except for the Ser product) the structures obtained correspond to $\mathrm{LDH}$ structures intercalated with organic anions.

An insight into the chemical environment of $\mathrm{Dy}^{3+}$ was attempted through XPS analysis of the 30:9:1 LDH and the Asp derivative (Figure 5). The Dy $4 \mathrm{~d} 5 / 3$ spectrum was detected in the $30: 9: 1 \mathrm{LDH}$ at $157 \mathrm{eV}$, which is a typical binding energy reported in dysprosium hydroxides [27] and oxides [28]. The large FWHM of $6 \mathrm{eV}$ in this spectrum suggests an irregular environment for dysprosium. Considering that the basal space detected by XRD was in agreement with a LDH structure with nitrate ions in the interlayer space and the FTIR spectrum clearly indicated that nitrate anions are free; then the $\mathrm{Dy}^{3+}$ cations could only be allocated in the octahedral sites of the layers and surrounded by hydroxide anions, thus remaining the different degrees of distortion in the dysprosium sites as a feasible explanation to the wide band observed by XPS. The Dy spectrum in the Asp derivative was not detected since the co-precipitation products of layered matrices also contain organic anions covering the outer crystallites surface [29] and this type of shell reduces the efficiency for the X-rays to reach the inorganic layers; even if some beams do, the content of dysprosium is low and the photoemission is not detected by the equipment. On the other hand, the $\mathrm{Zn} 2 \mathrm{p} 3 / 2$ spectrum in both samples presented the same symmetry with FWHM of $2.1 \mathrm{eV}$ (Figure 5), suggesting that the zinc sites were not affected with the intercalation of Asp anions.

Therefore, the incorporation of $\mathrm{Dy}^{3+}$ cations into the layers of the $\mathrm{LDH}$ was possible despite the large ionic radii, but the octahedral sites allocating this lanthanide are distorted.

Owing to the difficulty to analyze dysprosium by XPS, the EPR spectroscopy was conducted to all the organic intercalated samples (Figure 6). To collect an EPR spectrum of the paramagnetic Dy ${ }^{3+}$ cation $(I=5 / 2)$ is a difficult task since the unpaired electron in the $4 \mathrm{f}$ shell can be shielded with outer $5 \mathrm{~s}$ electrons. Maybe, due to this difficulty several EPR studies on materials doped with dysprosium do not report the spectra [30-32].

However, other authors have detected a signal with $g=$ 2.007 in strontium aluminates and sulfides doped with $\mathrm{Dy}^{3+}$ $[33,34]$, whose hyperfine splitting is coherent with $I=5 / 2$ [33]. In these reports, an additional absorption appeared in regions of $g$ values around 11,7 , and 4 , associated with low field resonance of $\mathrm{Dy}^{3+}$ [35]. These last signals fall within the range expected for $\mathrm{Dy}^{3+}[36]$; then the absorptions with $g=4.2$ in Figure 6 probably are originated from dysprosium cations. Since the signals are wide, it is only possible to confirm the paramagnetic properties in the 30:9:1 LDH and the Ser, PP, and Adip derivatives. The absorption near to $g=2.0$ appeared in the Ser and Asp derivatives. Since these are not present in the $30: 9: 1 \mathrm{LDH}$, then the absorption probably corresponds to radicals formed in the serine and adipate anions. In the literature, the $g=2.0$ signal has been observed in solid samples of calcium sulfate doped with dysprosium, and it was assigned to sulfate oxides radical but not to dysprosium [31].

\subsection{Photoluminescence}

3.3.1. Dysprosium Doped LDHs. The PL spectra of nitrate intercalated LDHs with different content of dysprosium are presented in Figure 7. The main emission of dysprosium atoms dispersed in inorganic matrices are found in the blue and yellow region when excited with photons in the range of $\lambda=350-387 \mathrm{~nm}$ [37-39]. The spectra of the two LDHs are formed by a wide band around $620 \mathrm{~nm}$, which could be considered as inhomogeneous broadening resulting from changes in the crystal field of the phosphorescent cation [17], but such situation is limited for our compounds since 

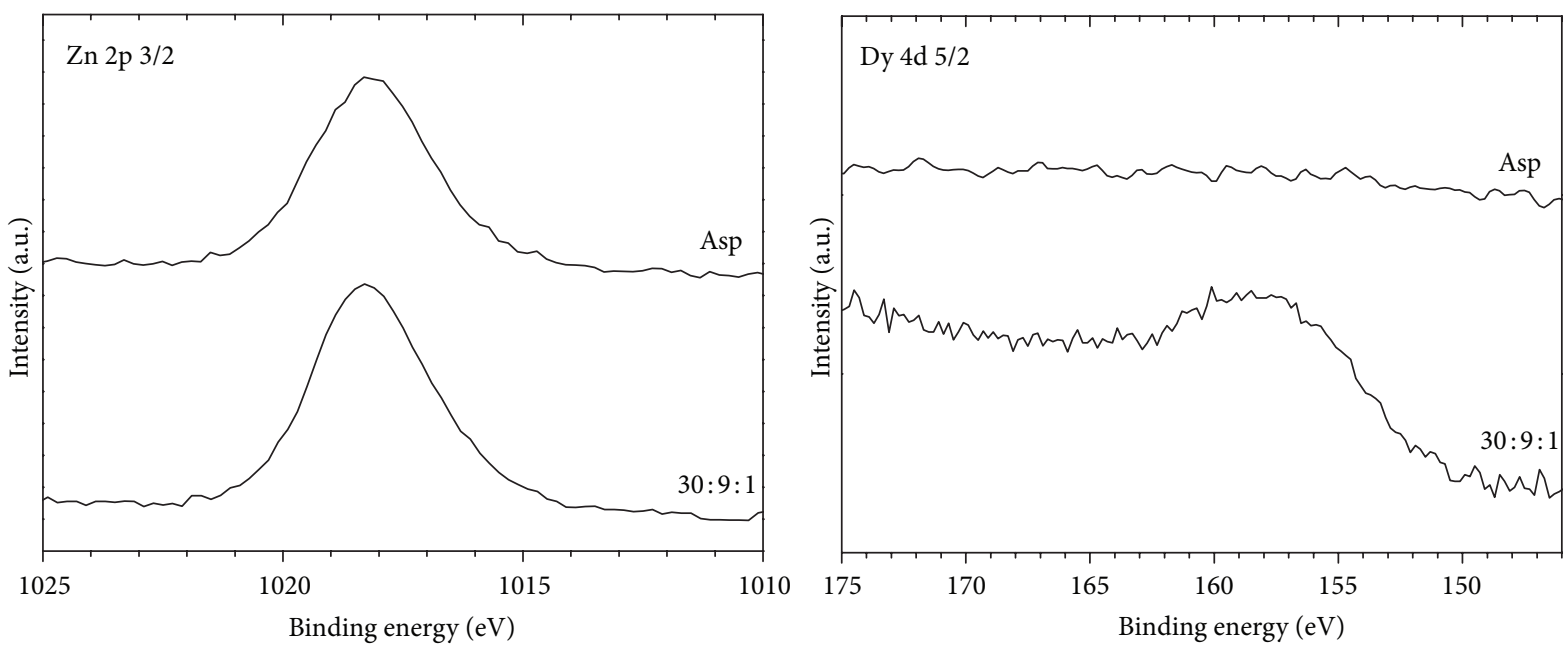

FIGURE 5: Zinc and dysprosium high-resolution XPS spectra of the $30: 9: 1 \mathrm{LDH}$ and the co-precipitation product with Asp.
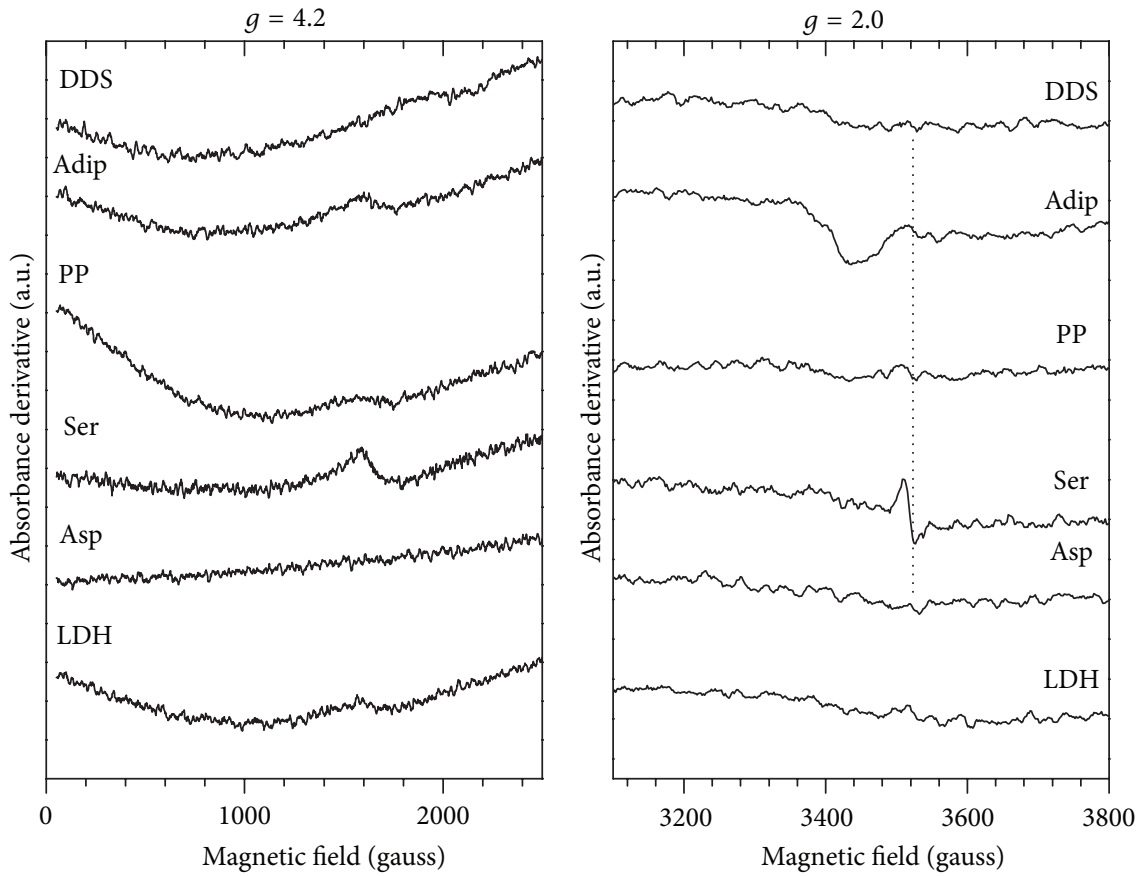

FIGURE 6: EPR spectra of the 30:9:1 LDH coprecipitated with L-aspartic acid (Asp), L-serine (Ser), phenyl phosphonic acid (PP), adipic acid (Adip), and sodium dodecylsulfate (DDS).

the $\mathrm{Dy}^{3+}$ cations are restricted to occupy octahedral sites surrounded by hydroxide anions or eventually by nitrate anions; otherwise, the XRD profiles in Figure 1 would not correspond to $\mathrm{LDH}$ structures. Thus, one probable fact changing the chemical environment is distortions in the octahedral sites allocating dysprosium, as it was also inferred from the XPS spectrum. The changes in the crystal field are known to contribute to the broadening of the $620 \mathrm{~nm}$ emission [17]. A second possible reason for this widening effect, which has not been well understood, is the contribution of the $\mathrm{LDH}$ lattice from $\mathrm{ZnO}$ defect centers [40, 41] or from $\mathrm{Zn}-\mathrm{OH}$ moieties [41]; this factor is likely contributing considering that the $30: 0: 10 \mathrm{LDH}$, which presented $\mathrm{ZnO}$ reflection in the XRD pattern presents the band centered at $\lambda=620 \mathrm{~nm}$ with higher relative intensity than the $30: 9: 1 \mathrm{LDH}$.

With respect to the dysprosium emission in the blue region $(468 \mathrm{~nm})$, the low intensity indicates a low contribution of the magnetic dipole $\left({ }^{4} \mathrm{~F}_{9 / 2}\right.$ to ${ }^{6} \mathrm{H}_{15 / 2}$ transition) because the $\mathrm{Dy}^{3+}$ cations are delocalized from the inversion center [37] in the two compounds. However, the relative intensity of the blue emission was higher in the 30:9:1 $\mathrm{LDH}$ suggesting that dysprosium cations achieved higher symmetry in comparison with the structure with higher dysprosium content $(30: 0: 10)$, whose red band at $620 \mathrm{~nm}$ 


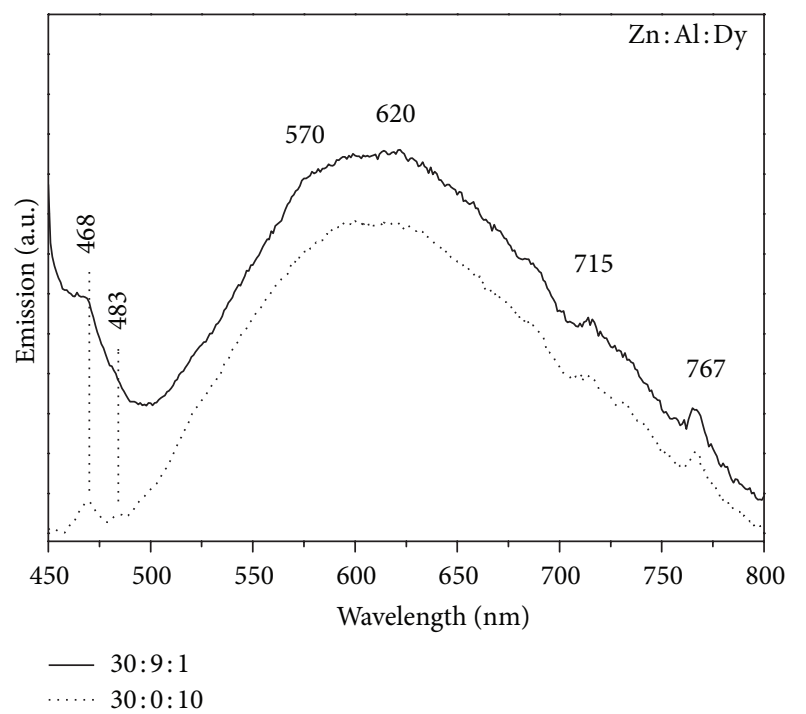

FIGURE 7: Emission spectra of LDH with different $\mathrm{Zn}$ : Al : Dy molar ratios. Excitation at $363 \mathrm{~nm}$.

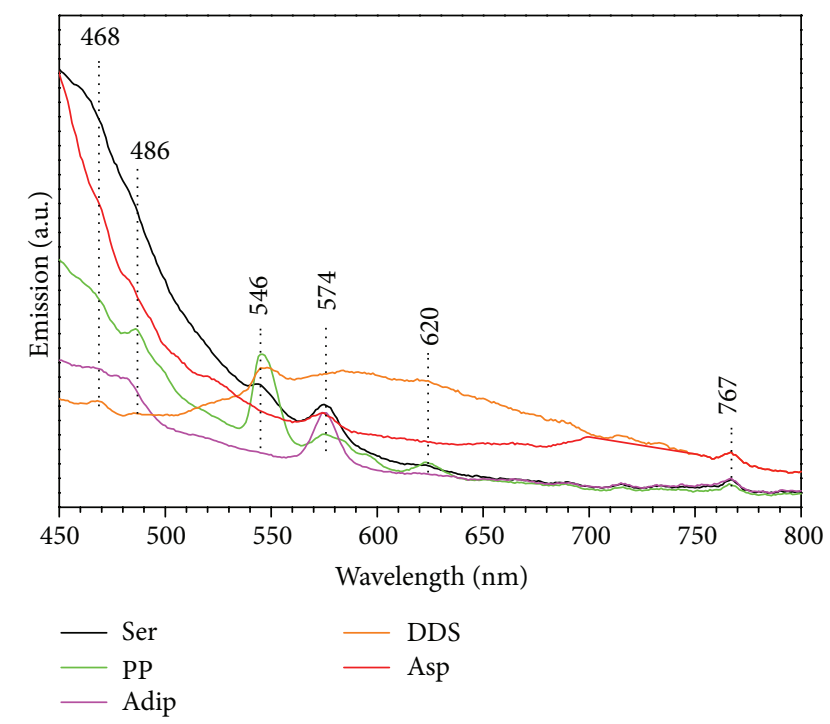

FIGURE 8: Emission spectra of the $30: 9: 1 \mathrm{LDH}$ coprecipitated with L-aspartic acid (Asp), L-serine (Ser), phenyl phosphonic acid (PP), adipic acid (Adip), and sodium dodecylsulfate (DDS). Excitation at $363 \mathrm{~nm}$.

has a higher relative intensity (due to the content of $\mathrm{ZnO}$ ) accompanied by the shoulder at $570 \mathrm{~nm}$, which is the yellow emission sensitive to crystalline modifications [37-39]; therefore, the high intensity of this shoulder indicates a high or diverse degrees of distortion in the coordination symmetry of dysprosium.

3.3.2. LDHs Intercalated with Organic Molecules. PL spectra of the organic intercalated LDHs (Figure 8) show narrower band emissions and a clear absence of the broad orange emission (except for the DDS). All compounds presented blue emission peaks between 468 and $480 \mathrm{~nm}$ (characteristic magnetic dipole transition ${ }^{4} \mathrm{~F}_{9 / 2} \rightarrow{ }^{6} \mathrm{H}_{15 / 2}$ in Dy), which appeared with higher relative intensity than the transitions of the electric dipole in the Asp, Adip PP, and Ser derivatives. Knowing that magnetic dipole transition depends on the crystal symmetry, the increased intensity indicates an improvement in crystallinity after the organic anion intercalation, which probably occurred because the organic species separate the inorganic layers allowing a rearrangement of the dysprosium octahedrons to increase the symmetry and the formation of inversion centers uniformly coordinated by hydroxyl groups.

Regarding the PP derivative, the intensity of the blue band $(486 \mathrm{~nm})$ is higher than the yellow emission $(574 \mathrm{~nm})$, but this spectrum contains a new peak at $546 \mathrm{~nm}$. The new band can be assigned to the interaction of $\mathrm{Dy}^{3+}$ with PP as ligand, since this anion has the capability to substitute some hydroxyl groups in LDHs [42]. In fact, a recent report described the lost of the common red emission $(620 \mathrm{~nm})$ of europium ions after the functionalization with phenylalanine, while a blue band ( $445 \mathrm{~nm}$ ) rose; the new band was explained due to the ligandmetal charge transference formed with functionalization [8]. For our case, the effect caused PP could be an explanation if functionalization did occurred; that is, the PP anions substituted some hydroxyl sites of the inorganic layers, thus changing the crystal field of $\mathrm{Dy}^{3+}$ ions. The consequence of the new crystal field was also reflected in the weak band at $620 \mathrm{~nm}$.

The PL spectrum of the DDS derivative presented a weak blue emission $(468 \mathrm{~nm})$ and a broad yellow emission from dysprosium centers overlapped with the $620 \mathrm{~nm}$ emission coming from $\mathrm{Zn}-\mathrm{O}$ regions. The activation mechanism of the band involving $\mathrm{Zn}$ needs further studies, since its presence occurred only in nitrate intercalated LDHs and in the PP and DDS derivatives. Similarly, studies are required for the anomalous emission observed at $546 \mathrm{~nm}$ in the PP, DDS, and Ser derivatives. This band has not been reported for dysprosium, zinc oxide/hydroxides, or aluminate, neither can be associated with the organic anions, since the band was present in the nitrate intercalated samples contributing to enlarge the main emission band, but it raises monochromatized when the inorganic layer interacts with PP, DDS, and Ser.

On the other hand, the yellow emission of dysprosium at $574 \mathrm{~nm}$ becomes narrower in the derivatives where carboxylate anions are present like Asp, Adip, and Ser. In the last case of Ser, as the effect does not seem to depend on intercalation, then a probable effect of ligands is present.

Finally, the weak band at $767 \mathrm{~nm}$ of unknown origin was present in all LDHs samples. Since this emission is independent of the functional groups in the organic anion, this could be useful for monitoring dysprosium-doped LDH as biological probes; additionally, the energy of this emission is near to that of the IR light, which is able to pass through cell walls and tissues.

\section{Conclusions}

The precipitation of the LDHs with different $\mathrm{Zn}^{2+}: \mathrm{Al}^{3+}$ : $\mathrm{Dy}^{3+}$ molar ratio was conducted. The $30: 9: 1 \mathrm{LDH}$ comprised 
a single crystal phase with free nitrate ions intercalated. Wide PL spectrum of the yellow emission of dysprosium $(574 \mathrm{~nm})$ suggested that the coordination environment of $\mathrm{Dy}^{3+}$ has different degrees of distortion, matching with the information obtained by XPS. Along the yellow emission, a red emission $(620 \mathrm{~nm})$ from zinc centers was detected, which was retained in the DDS derivative in contrast with the LDHs intercalated with PP, Asp, Adip, and Ser anions where the yellow dysprosium emission became narrow, while the broad red contribution from zinc centers disappeared. Then, the emission of $\mathrm{Dy}^{3+}$ is influenced by ligands. The emission of unknown origin at $767 \mathrm{~nm}$ in all LDHs samples could be useful for optical probes once this type of light is able to transpose cell walls.

\section{Acknowledgments}

This work was supported by PROMEP (UDG-PTC-1055). Authors are grateful to J. A. Diaz Hernandez and Professor Wencel de la Cruz for providing the access to the XPS spectrometer at $\mathrm{CNyN}-\mathrm{UNAM}$ and indebt to Professor A. S. Mangrich for his helpful assistance in the EPR measurements. Gustavo A. Hirata acknowledges the support from DGAPAUNAM (Grant IN-109913).

\section{References}

[1] S. Carlino, "The intercalation of carboxylic acids into layered double hydroxides: a critical evaluation and review of the different methods," Solid State Ionics, vol. 98, no. 1-2, pp. 73-84, 1997.

[2] M. Rajamathi, G. S. Thomas, and P. V. Kamath, "The many ways of making anionic clays," Proceedings of the Indian Academy of Sciences, vol. 113, no. 5-6, pp. 671-680, 2001.

[3] C. Forano, T. Hibino, F. Leroux, and C. Taviot-Guéhto, "Fluorescence of $\mathrm{Zn}$-Al-Eu ternary layered hydroxide response to phenylalanine," in Handbook of Clay Science, F. Bergaya, B. K. G. Theng, and G. Lagaly, Eds., Developments in Clay Science, pp. 1021-1096, Elsevier, Amsterdam, The Netherlands, 1st edition, 2006.

[4] J. J. Bravo-Suárez, E. A. Páez-Mozo, and S. T. Oyama, "Review of the synthesis of layered double hydroxides: a thermodynamic approach," Quimica Nova, vol. 27, no. 4, pp. 601-604, 2004.

[5] C.-C. Yang, S.-Y. Chen, and S.-Y. Cheng, "Synthesis and physical characteristics of $\mathrm{ZnAl}_{2} \mathrm{O}_{4}$ nanocrystalline and $\mathrm{ZnAl}_{2} \mathrm{O}_{4} / \mathrm{Eu}$ core-shell structure via hydrothermal route," Powder Technology, vol. 148, no. 1, pp. 3-6, 2004.

[6] Y. Chen, F. Li, S. Zhou, J. Wei, Y. Dai, and Y. Chen, "Structure and photoluminescence of Mg-Al-Eu ternary hydrotalcite-like layered double hydroxides," Journal of Solid State Chemistry, vol. 183, no. 9, pp. 2222-2226, 2010.

[7] Y. Chen, S. Zhou, F. Li, F. Li, and Y. Chen, "Photoluminescence of Eu-doped ZnAl-LDH depending on phase transitions caused by annealing temperatures," Journal of Luminescence, vol. 131, no. 4, pp. 701-704, 2011.

[8] Y. Chen, F. Li, G. Yu, and X. Yang, "Fluorescence of ZnAl-Eu ternary layered hydroxide response to phenylalanine," Spectrochimica Acta A, vol. 86, pp. 625-630, 2012.
[9] R. D. Shannon, "Revised effective ionic radii and systematic studies of interatomic distances in halides and chalcogenides," Acta Crystallographica A, vol. 32, pp. 751-767, 1976.

[10] C. Li, G. Wang, D. G. Evans, and X. Duan, "Incorporation of rare-earth ions in $\mathrm{Mg}-\mathrm{Al}$ layered double hydroxides: intercalation with an [Eu(EDTA)]-chelate," Journal of Solid State Chemistry, vol. 177, no. 12, pp. 4569-4575, 2004.

[11] J. Wang, J. Zhou, Z. Li et al., "Design of magnetic and fluorescent $\mathrm{Mg}$-Al layered double hydroxides by introducing $\mathrm{Fe}_{3} \mathrm{O}_{4}$ nanoparticles and $\mathrm{Eu}^{3+}$ ions for intercalation of glycine," Materials Research Bulletin, vol. 45, no. 5, pp. 640-645, 2010.

[12] L. Sarakha, C. Forano, and P. Boutinaud, "Intercalation of luminescent Europium(III) complexes in layered double hydroxides," Optical Materials, vol. 31, no. 3, pp. 562-566, 2009.

[13] X. Gao, M. Hu, L. Lei et al., "Enhanced luminescence of europium-doped layered double hydroxides intercalated by sensitiser anions," Chemical Communications, vol. 47, no. 7, pp. 21042106, 2011.

[14] F. Chen, Y.-J. Zhu, K.-H. Zhang et al., "Europium-doped amorphous calcium phosphate porous nanospheres: preparation and application as luminescent drug carriers," Nanoscale Research Letters, vol. 6, article 67, 2011.

[15] U. Costantino, V. Ambrogi, M. Nocchetti, and L. Perioli, "Hydrotalcite-like compounds: versatile layered hosts of molecular anions with biological activity," Microporous and Mesoporous Materials, vol. 107, no. 1-2, pp. 149-160, 2008.

[16] C. del Hoyo, "Layered double hydroxides and human health: an overview," Applied Clay Science, vol. 36, no. 1-3, pp. 103-121, 2007.

[17] G. Blasse and B. C. Grabmaier, Luminescent Materials, Springer, New York, NY, USA, 1st edition, 1994.

[18] G. G. C. Arizaga, A. S. Mangrich, and F. Wypych, " $\mathrm{Cu}^{2+}$ ions as a paramagnetic probe to study the surface chemical modification process of layered double hydroxides and hydroxide salts with nitrate and carboxylate anions," Journal of Colloid and Interface Science, vol. 320, no. 1, pp. 238-244, 2008.

[19] G. G. C. Arizaga, A. S. Mangrich, J. E. F. da Costa Gardolinski, and F. Wypych, "Chemical modification of zinc hydroxide nitrate and Zn-Al-layered double hydroxide with dicarboxylic acids," Journal of Colloid and Interface Science, vol. 320, no. 1, pp. 168-176, 2008.

[20] S. Aisawa, S. Takahashi, W. Ogasawara, Y. Umetsu, and E. Narita, "Direct intercalation of amino acids into layered double hydroxides by coprecipitation," Journal of Solid State Chemistry, vol. 162, no. 1, pp. 52-62, 2001.

[21] Y.-F. Chao, J.-J. Lee, and S.-L. Wang, "Preferential adsorption of 2,4-dichlorophenoxyacetate from associated binary-solute aqueous systems by $\mathrm{Mg} / \mathrm{Al}-\mathrm{NO}_{3}$ layered double hydroxides with different nitrate orientations," Journal of Hazardous Materials, vol. 165, no. 1-3, pp. 846-852, 2009.

[22] G. R. Williams and D. O'Hare, "New phosphonate intercalates of $\left[\mathrm{Ca}_{2} \mathrm{Al}(\mathrm{OH})_{6}\right] \mathrm{NO}_{3} \cdot y \mathrm{H}_{2} \mathrm{O}$ : a synthetic and kinetic study," Solid State Sciences, vol. 8, no. 8, pp. 971-980, 2006.

[23] D. C. Pereira, D. L. A. de Faria, and V. R. L. Constantino, "CuII hydroxy salts: characterization of layered compounds by vibrational spectroscopy," Journal of the Brazilian Chemical Society, vol. 17, no. 8, pp. 1651-1657, 2006.

[24] S. Aisawa, H. Kudo, T. Hoshi et al., "Intercalation behavior of amino acids into Zn-Al-layered double hydroxide by calcination-rehydration reaction," Journal of Solid State Chemistry, vol. 177, no. 11, pp. 3987-3994, 2004. 
[25] R. Chitrakar, Y. Makita, A. Sonoda, and T. Hirotsu, "Synthesis of a novel layered double hydroxides $\left[\mathrm{MgAl}_{4}(\mathrm{OH})_{12}\right](\mathrm{Cl})_{2} \cdot 2.4 \mathrm{H}_{2} \mathrm{O}$ and its anion-exchange properties," Journal of Hazardous Materials, vol. 185, no. 2-3, pp. 1435-1439, 2011.

[26] S. A. Hindocha, L. J. McIntyre, and A. M. Fogg, "Precipitation synthesis of lanthanide hydroxynitrate anion exchange materials, $\mathrm{Ln}_{2}(\mathrm{OH})_{5} \mathrm{NO}_{3} \cdot \mathrm{H}_{2} \mathrm{O}(\mathrm{Ln}=\mathrm{Y}, \mathrm{Eu}-\mathrm{Er})$," Journal of Solid State Chemistry, vol. 182, no. 5, pp. 1070-1074, 2009.

[27] M. Salavati-Niasari, J. Javidi, F. Davar, and A. A. Fazl, "Sonochemical synthesis of $\mathrm{Dy}_{2}\left(\mathrm{CO}_{3}\right)_{3}$ nanoparticles and their conversion to $\mathrm{Dy}_{2} \mathrm{O}_{3}$ and $\mathrm{Dy}(\mathrm{OH})_{3}$ : effects of synthesis parameters," Journal of Alloys and Compounds, vol. 503, no. 2, pp. 500506, 2010.

[28] National Institute of Standards and Technology, "X-ray photoelectron spectroscopy database," February 2012, http://srdata .nist.gov/xps/.

[29] G. G. C. Arízaga, "Intercalation studies of zinc hydroxide chloride: ammonia and amino acids," Journal of Solid State Chemistry, vol. 185, pp. 150-155, 2012.

[30] B. Sanyal, V. Natarajan, S. P. Chawla, and A. Sharma, "TL and EPR studies of $\mathrm{CaSO}_{4}$ :Dy phosphor to investigate its efficacy in measurement of food irradiation dose at sub-ambient temperatures," Radiation Measurements, vol. 45, no. 8, pp. 899-905, 2010.

[31] A. K. Bakshi, B. Sanyal, V. J. Joshi, M. K. Bhide, V. Natarajan, and A. Sharma, "EPR-TL correlation studies on Bi co-doped $\mathrm{CaSO}_{4}:$ :Dy phosphor," Applied Radiation and Isotopes, vol. 69, no. 1, pp. 254-260, 2011.

[32] F. N. Bukhanko, N. A. Doroshenko, and V. I. Kamenev, "Micromagnetism of $\mathrm{DyBa}_{2} \mathrm{Cu}_{3} \mathrm{Oy}$ compounds," Journal of Magnetism and Magnetic Materials, vol. 242-245, part 2, pp. 1100-1102, 2002.

[33] E. I. Anila and M. K. Jayaraj, "Effect of dysprosium doping on the optical properties of SrS:Dy,Cl phosphor," Journal of Alloys and Compounds, vol. 504, no. 1, pp. 257-260, 2010.

[34] T. Takeyama, T. Nakamura, N. Takahashi, and M. Ohta, "Electron paramagnetic resonance studies on the defects formed in the Dy(III)-doped $\mathrm{SrAl}_{2} \mathrm{O}_{4}$," Solid State Sciences, vol. 6, no. 4, pp. 345-348, 2004.

[35] M. R. Gafurov, V. A. Ivanshin, I. N. Kurkin et al., "EPR study of some rare-earth ions $\left(\mathrm{Dy}^{3+}, \mathrm{Tb}^{3+}\right.$, and $\left.\mathrm{Nd}^{3+}\right)$ in $\mathrm{YBa}_{2} \mathrm{Cu}_{3} \mathrm{O}_{6}$ compound," Journal of Magnetic Resonance, vol. 161, no. 2, pp. 210-214, 2003.

[36] J.-X. Li, Z.-X. Du, B.-L. Zhu et al., "A bimetallic CoIIDyIII complex bridged by oxydiacetate ligand: synthesis, structure, magnetic, spectral and TG properties of $\left\{\left[\mathrm{DyCo}(\mathrm{oda})_{3}\right]_{4}\right.$ $\left.\left[\mathrm{Co}\left(\mathrm{H}_{2} \mathrm{O}\right)_{6}\right]_{2} \cdot 6 \mathrm{H}_{2} \mathrm{O}\right\} \mathrm{n}$," Inorganic Chemistry Communications, vol. 14, no. 4, pp. 522-525, 2011.

[37] K. N. Shinde, S. J. Dhoble, and A. Kumar, "Combustion synthesis of $\mathrm{Ce}^{3+}, \mathrm{Eu}^{3+}$ and $\mathrm{Dy}^{3+}$ activated $\mathrm{NaCaPO}_{4}$ phosphors," Journal of Rare Earths, vol. 29, no. 6, pp. 527-535, 2011.

[38] M. Li, G. M. Ganea, C. Lu et al., "Lipophilic phosphoniumlanthanide compounds with magnetic, luminescent, and tumor targeting properties," Journal of Inorganic Biochemistry, vol. 107, no. 1, pp. 40-46, 2012.

[39] G. Seeta Rama Raju, H. C. Jung, J. Y. Park et al., "Synthesis and luminescent properties of Dy ${ }^{3+}$ :GAG nanophosphors," Journal of Alloys and Compounds, vol. 481, no. 1-2, pp. 730-734, 2009.

[40] P. Li, S. Wang, J. Li, and Y. Wei, "Structural and optical properties of Co-doped $\mathrm{ZnO}$ nanocrystallites prepared by a one-step solution route," Journal of Luminescence, vol. 132, no. 1, pp. 220-225, 2012.
[41] Y.-C. Liang, "Growth and physical properties of three-dimensional flower-like zinc oxide microcrystals," Ceramics International, vol. 38, no. 2, pp. 1697-1702, 2012.

[42] A. Shimamura, E. Kanezaki, M. I. Jones, and J. B. Metson, "Direct observation of grafting interlayer phosphate in $\mathrm{Mg} / \mathrm{Al}$ layered double hydroxides," Journal of Solid State Chemistry, vol. 186, pp. 116-123, 2012. 

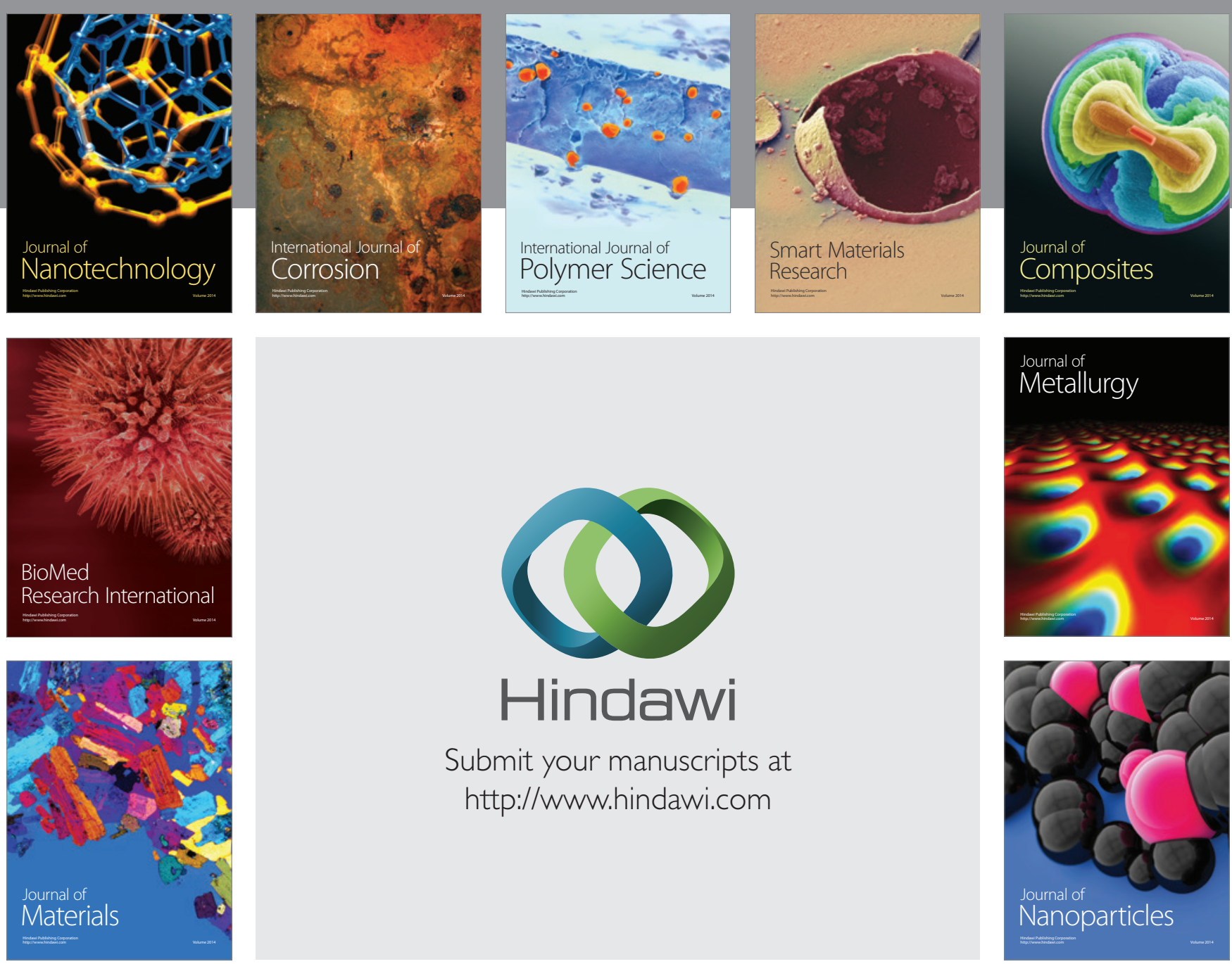

Submit your manuscripts at http://www.hindawi.com
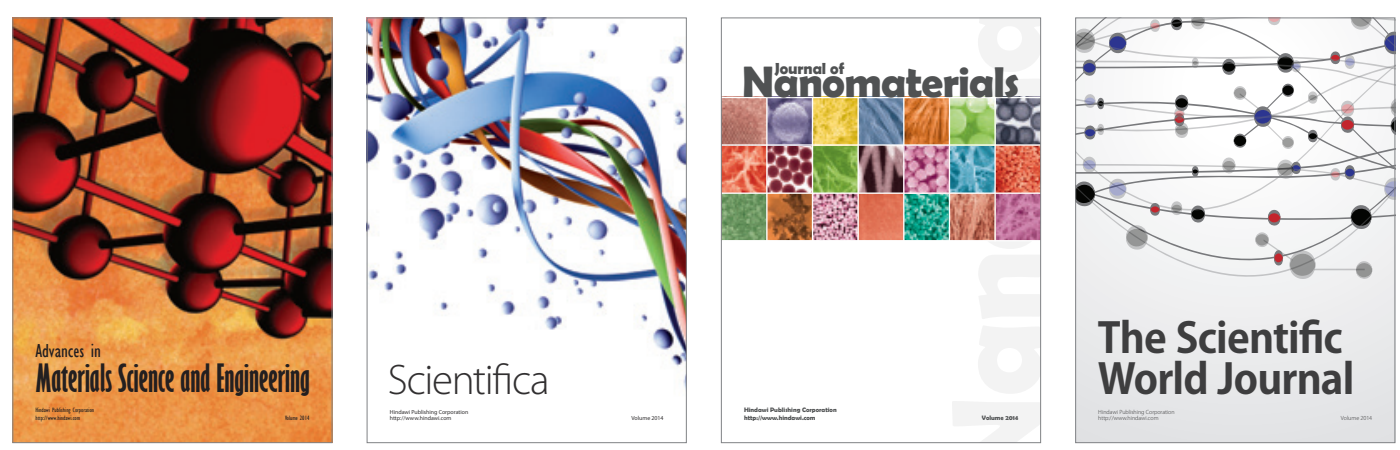

\section{The Scientific World Journal}
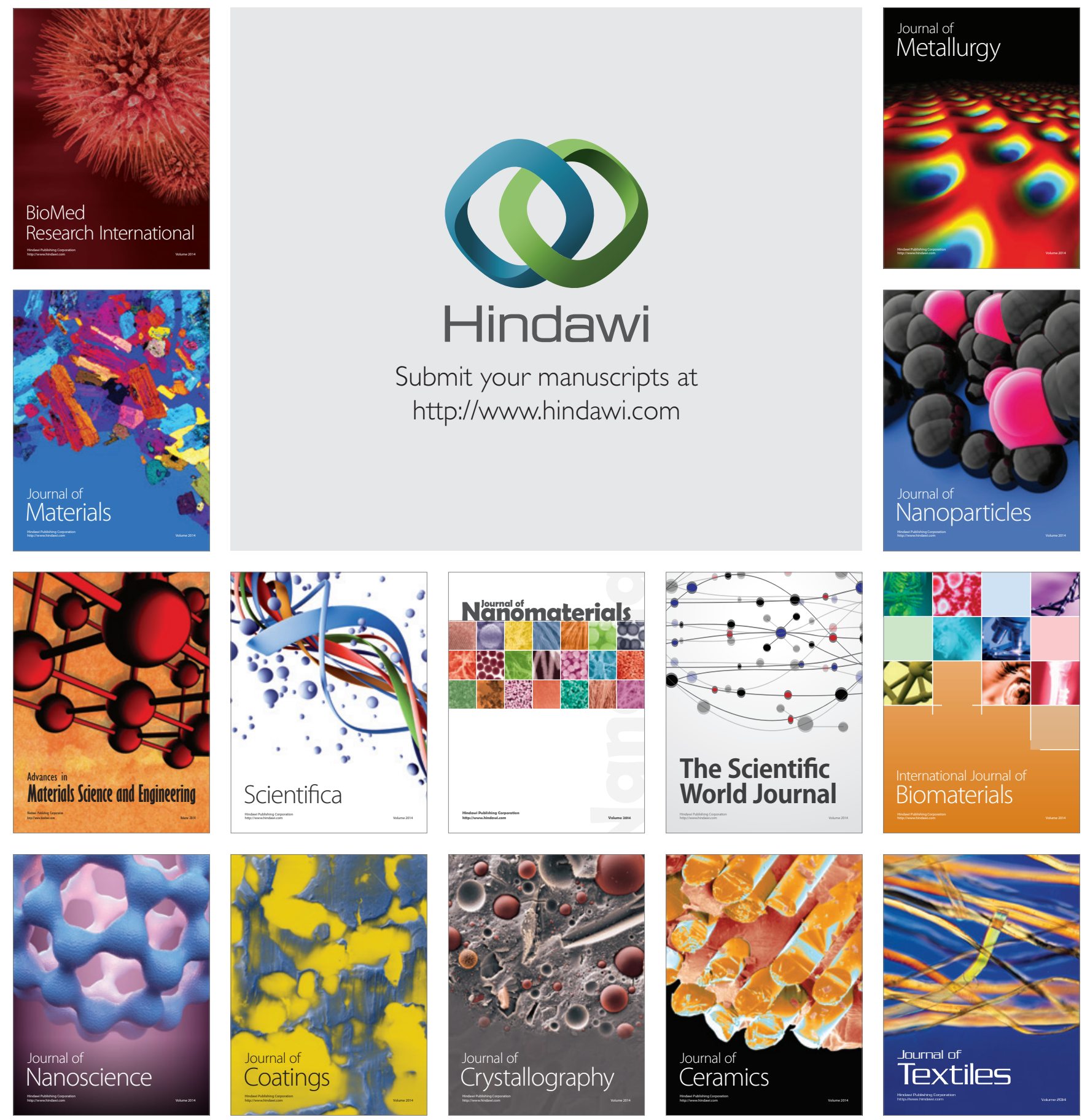